This is the version of the article accepted for publication in Structural Change and Economic Dynamics published by Elsevier

https://doi.org/10.1016/j.struec0.2018.11.003

Accepted version downloaded from SOAS Research Online:

https://eprints.soas.ac.uk/30111/

Special issue of Structural Change and Economic Dynamics

Frontiers of Industrial Policy: Structures, Institutions and Policies.

Guest editors ${ }^{1}$ : Antonio Andreoni, Ha-Joon Chang and Roberto Scazzieri

Introduction Article

\title{
Industrial Policy in Context: building blocks for an integrated and comparative political economy agenda
}

Antonio Andreoni, Ha-Joon Chang and Roberto Scazzieri

\section{Introduction}

Over the past two decades the global manufacturing landscape has been reshaped by profound structural transformations. The rise of new industrial powers, China in particular, has led to the restructuring of global production systems and changes in global trade patterns. These structural dynamics have been due both to changes within and to increasing interdependencies across national manufacturing systems, their constituent sectoral value chains, productive organisations and technologies.

\footnotetext{
1 Antonio Andreoni (Department of Economics, SOAS University of London and South African Research Chair in Industrial Development, University of Johannesburg)

Ha-Joon Chang (Faculty of Economics and Centre of Development Studies, University of Cambridge) Roberto Scazzieri (Department of Economics, University of Bologna; Accademia Nazionale dei Lincei, Roma; Gonville and Caius College and Clare Hall, Cambridge) 
Over this period, and increasingly in the current conjuncture, major industrialised and emerging economies have reacted to (and, sometimes, proactively triggered) these structural transformations by adopting a wide range of industrial, manufacturing and technology policies. In the least developed countries, industrial policies have regained central stage after decades of structural adjustments, although several global and national political economy factors have hampered their adoption and implementation. Notwithstanding these differences across countries, overall industrial policies have played a major role in driving the transformation of national manufacturing systems and changing the global distribution of production, power and wealth among nations and regions.

The frontiers of industrial policy have been pushed ahead and reshaped by governments over the last two decades. More countries, more resources and a broader variety of both supply and demand side instruments have been deployed over the last two decades. The reason for this increasing variety is due to two main factors. First, even when governments have adopted the same policy instruments, these instruments have been implemented differently according to each country's industrial organisation and structure, institutional setting, and political economy situation (Andreoni, 2016). Second, over this period, the policy frameworks - i.e. the degrees and the type of targeting, governance models, and policy instruments - underlying the implementation of industrial policy have changed and dominant policy paradigms have been replaced by new ones.

Between the mid- 1990s and the first half of the 2000s, in mature industrialised economies like the United States, industrial policies were mainly inspired by an innovation-focused framework, and were largely disguised under several other names - competitiveness, science and technology policy - and implemented by nonindustrial agencies or ministries (Block and Keller, 2011). Indeed, the disguise of industrial policy was an effective form of 'kicking away the ladder', as it perpetuated the myth that successful economies do not practise industrial policy, which has been used for persuading the developing economies not to use such a policy (Chang, 2002a). Despite this, fast-industrialising economies - China in particular, but also middle-income countries like Malaysia and Brazil - implemented industrial policies more openly and managed to transform a number of manufacturing and resourcebased sectors (Andreoni and Tregenna, 2018). These late-industrialisers upgraded their industrial structure in low- and medium-tech sectors, while gaining global production and market shares in a number of high-tech sectors.

During this period, the industrial policy debate focusing on mature industrial economies was largely subsumed under the innovation systems literature and was centred on innovation and technology policy issues (Soete, 2007). The debate on industrial policy within the development economics literature remained locked into the 'unproductive confrontations' started in the 1980s and continued in the 1990s (Chang, 2011a). Theoretical debates on picking winners, horizontal versus vertical interventions, and market failures, in which many participants took extreme positions, dominated the developmental industrial policy literature until the mid- 2000s (for a critique see Chang, 1994a; Andreoni and Chang, 2016). 
The global financial crisis in the late 2000s, and the following economic depression, led to two important shifts in the theory and the practice of industrial policy in the industrialised economies. First, in terms of policy practice, a number of economies introduced strategies addressing deindustrialisation, declining industrial competitiveness and, thus, industrial restructuring. Second, in theoretical terms, they gradually moved away from an innovation-centred framework to rediscover the key role of production in an innovation-driven economy (Andreoni et al., 2018). During the same period, the fast-industrialising countries have pushed forward their own industrial policy frontiers by focusing on increasing value addition and competitiveness in a number of medium- and high-tech sectors, including ICT, complex-system products, and machinery industries (Zhou et al., 2016; Best, 2018)

In response to this shift in the industrial policy practice across the world, a number of scholars have described this phase as a 'new industrial policy revolution' (Stiglitz and Lin, 2013; Stiglitz et al., 2013). While this rediscovery has revived the tradition of country case studies and the focus on a number of specific policy instruments and institutions, contributions have mainly been based on single-country case studies, with a view of learning from successes and failures. While offering important insights, these contributions have been mainly framed within the market-failure and the information-economics paradigms and, as a result, have overlooked a number of key policy domains that were central in the earlier industrial policy debates (Andreoni and Chang, this issue).

More recently, with the first signs of economic recovery in the global North, mature industrial economies have explored new frontiers of technology policy, with a focus on long-term grand challenges, like climate change and the impact of emerging technologies (e.g., digitalisation, nanotechnology, biotechnology and advanced materials) (Berger, 2013; Andreoni, 2017). The interest in the so-called Fourth Industrial Revolution has gained momentum across the emerging economies and the least developed countries as well. However, while the former group of countries have built up solid production and technology bases to capture some of the arising technological opportunities, the latter have been increasingly distracted by this new paradigm under the illusion of a miraculous jump to the next industrial revolution (Andreoni and Chang, 2017).

The latest contributions in the industrial policy literature have mainly focused on these most recent industrial policies and pointed to the 'novelty' of some of these experiences and the potential disruptions associated with technological and climate change (Foray et al. 2012). Particular emphasis has been given to the 'new' industrial policy rationales and the opportunities offered by specific 'new' policy areas, such as those targeting green industrial and technology transitions (Rodrik, 2014).

While the emerging themes are important ones, the recent industrial policy debate has been narrowing its focus in three main respects.

First, it has increasingly lost contact with the historical and context-specific dynamics of production transformation. As a result, recent contributions have often overlooked the specific challenges countries face in benefitting from technological change and global production. For example, little attention has been paid to the fact that the 
effective absorption, adoption and diffusion of emerging technologies require building production capabilities and organisations. Without these in place, technologies like ICT and emerging ones like digital systems can only have a limited transformative impact in the economy. They have also missed many of the new industrial policy challenges countries are facing today. For example, these contributions have failed to recognise the extent to which industrial polarisation across and within countries is threatening social and economic sustainabilities. For another example, they have ignored the negative impacts that the breaking of the profit-investment nexus within enterprises is having on investments, productivity and innovation.

Second, and in relation to the former issue, industrial policy has been mainly framed as a 'technical' or 'market failure/information' problem, with little (or no) attention to the political economy of production transformation in specific sectors and countries. As a result, the different target priorities of governments in different countries and the different feasibilities of certain types of structural transformation in different countries have been often misunderstood. Simplistic 'good governance' and 'good business environment' agendas have come to replace an understanding of the institutional political economy dynamics in particular contexts.

Finally, the recent contributions to the industrial policy debate have lost the ambition to provide an integrated industrial policy framework that captures changes in micro-, meso- and macro- structures and institutions, and their interdependent and contextdependent dynamics. Ultimately production transformation involves several policy domains, from the traditional supply-side ones to those related to financial and macroeconomic regulations, the welfare state, and institutional development. The lack of consideration of these policy domains and the way in which they affect (and are affected by) production transformation is another shortcoming of the more recent contributions to the industrial policy debate.

The present special issue aims at addressing some of these gaps by providing analyses of the frontiers of industrial policy theory and practice in different productive and country contexts. Specifically, it does so by providing contributions towards a more integrated theoretical framework based on comparative political economy for industrial policy analysis and practice.

\section{The political economy of production transformation: back to the structural-institutional-policy nexus}

Industrial policy is ultimately a policy about production. For this reason, the conditions for effective industrial policy cannot be adequately addressed unless we enter the 'black box' of the production system and disentangle the policy options that are structurally available in it (Rosenberg, 1982; ; Scazzieri, 1993, 1999; Landesmann and Scazzieri, 1996a, 1996b; Andreoni, 2014; Andreoni and Scazzieri, 2014; Marengo and Scazzieri, 2014). This approach should be grounded in detailed investigation of the production processes and capabilities and of the transformations that industrial policy measures can introduce in specific processes or sectors (Andreoni and Chang, 2017; Best, 2018a). 
Production transformation is a structural process centred around productive organisations, and involving a plurality of networked organisations and other institutions - for example, those focusing on financing productive investments or those supporting skills development and technology scaling-up. These productive organisations and institutions are thus part of a broader production system, that is, a multi-layered arrangement of interdependencies between productive units.

These productive units can be analysed at different levels of aggregation and, in doing so, multiple interdependences within the individual workshop (or establishment) as well as between networks of productive units within and across industries can be identified and exploited with appropriate policy instruments. These critical interdependencies are different from one industrial system to another, in particular with respect to the overall hierarchical structure those links generate. As a result of these structural differences, different economic systems will respond very differently to the same industrial policy measures. Policy measures that trigger industrial transformation and industrial growth in certain cases may be ineffective, or even counterproductive, in other cases.

Industrial policy often leads to structural changes (even when it is not intended), as policy measures influencing the industrial system generally do so by triggering changes in the relative proportions between different industries or different verticallyintegrated lines of production. This highlights the need to make industrial policy sensitive to the morphology of structural dynamics in each economy or industry. For example, structural dynamics may follow very different trajectories depending on whether the dominant dynamic follows 'vertical' transformation lines along production filières or 'horizontal' lines of connectivity joining different filières through reciprocal feedback loops. Structural change will therefore unfold along different trajectories, depending on the organisational structure of the industrial system. In particular, structural dynamics will take a different character, depending on whether horizontal or vertical linkages are dominant.

Horizontal linkages highlight structural dynamics whose salient features are the transformations in the characteristics of the processes delivering intermediate inputs to one another and/or the transformations in the type of interdependence between those processes within a certain 'production space' (Andreoni, 2018). The switch from one matrix of interdependencies to another in a production system that is subject to limited availability of non-produced resources (e.g., land) is a case in point and has been addressed as such at least since Malthus' and Ricardo's analysis of decreasing returns (Quadrio Curzio, 1996; Andreoni, 2015). For another example, increasing returns can result from structural processes of reconfiguration of these interdependencies, provided that certain scale and proportionality conditions within and across firms are satisfied (Scazzieri, 2014). In contrast, vertical linkages call attention to structural dynamics whose salient features are the transformations in the vertically-integrated sectors, leading from primary inputs to final products, as well as the transformations in the relative proportions between those sectors (Pasinetti, 1981; Syrquin,1988). Radically different structural dynamics may arise in the case of shifts from vertical to horizontal linkages, and vice versa. 
Thus seen, from a structuralist perspective, industrial policy aims at reshaping the industrial structure and the organisational configuration of the production system and thus setting the economy towards a feasible path of structural transformation. However, industrial policy is also about managing the complex process of institutional building and change that accompany any process of structural transformation (Chang, 1994b; Chang, 2002b and 2011b).

Indeed, institutional development and regulatory re-engineering are critical in the implementation of any industrial policy. For example, technology policies require the establishment of intermediate technology institutions, the setting-up of standards, and the creation of coordination agencies to align the actions of relevant organisations. Skills policies would not exist without adequate coordination between vocational training institutions and productive organisations. Long-term capital-intensive investments (including infrastructural investments) would not be possible without specialised financing institutions, like development banks. Finally, central banks and other institutions of macroeconomic management are critical in assuring that the economy remain on a sustainable path of transformation (Andreoni et al., 2017; Chang and Andreoni, 2019).

The link between structures and institutions, and the way in which policies influence each of them, is thus central in the analysis of industrial policy. This structureinstitution-policy nexus is ultimately shaped by the specific political economy dynamics and the economic dynamics of a certain country, regions or sector of the economy. From the value distribution between workers, managers and shareholders within enterprises, to the way in which industrial policies favour certain groups or sectors vis a vis others, production transformation entails political economy dynamics which constantly reshape the distribution of interests, incentives, and resources in the economy.

The above framework draws attention to the need for a new approach to industrial policy, which should distance itself from a priori assumptions concerning the desirability and the effectiveness of the policy instruments to be used and pay attention to the complex nexuses linking structures, institutions and policies in a particular context (be it a country, a cluster of industries, or individual industries). In analysing these nexuses, the following three issues are of particular relevance.

First, it should be recognised that industrial policy can be only understood 'in context', that is, by analysing the specific structural, organisational, institutional and political economy features of production systems, in a certain country or region, and how these features change over time. This means that the industrial policy debate cannot simply focus on general global technology trends and abstract theoretical speculations. Industrial policy research should pay far more attention to the analysis of 'context-specific' production structures, including how organisations operate and institutions function, and how these processes are affected by (often overlooked) political economy dynamics.

Second, industrial policy can be better assessed from a comparative perspective, that is, by comparing countries' experiences at similar stages of development, as well as through the rediscovery of historical cases . The adoption of a 'comparative political 
economy' perspective is critical in identifying the specific features of a certain context. While the global context changes over time and while different countries have different histories, comparative political economy analyses will help in framing and disentangling the critical interdependencies linking structures, institutions and policies in different contexts and at different point in global history.

Third, industrial policy analyses cannot be reduced to a mere 'technical problem' within a market economy framework. Industrial policy is ultimately about production understood as the main 'structure of living together' within an 'organizational economy’ framework (Simon, 1991; Andreoni and Chang, 2017). This means that production organisations - not markets - are the main structures in which the polity and the society are embedded and, therefore, that the governance of these organisations and systems are critical in guaranteeing their reproduction, inclusiveness, and sustainability.

\section{The contributions in this special issue}

This special issue highlights the context-dependent nature of effective industrial policy through the examination of a variety of cases. The contributions in this special issue also provides an integrated treatment of major industrial policy domains and their complex interdependences. The papers are organised in four main groups and overall provide evidence on several countries and regions, including the US, the European periphery, Japan, Korea, Bangladesh, Malaysia, Thailand, Brazil and the Sub-Saharan African economies.

The first two papers by Landesmann and Stollinger, 2018 and Bianchi and Labory, 2018 frame today's global industrial policy context by investigating the main features of the recent changes in global economic structure and manufacturing regimes. While the first paper focuses on the transformations of global production and trade dynamics and their impacts on the European periphery countries, the second one looks at these transformations through the technological and organisational lenses of different manufacturing regimes.

Landesmann and Stollinger, 2018 provides empirical evidence of the global structural change, led by the involvements of the emerging economies in international production networks through new forms of trade in tasks. The shifts in global production and trade shares have resulted in radical changes in the positions of countries in global value chains due to rather rapid technological and human capital up-grading in some of these economies. Building on the assessment of these transformations, the paper focuses on the European context and the specific contextual challenges faced by its low- and medium-income economies. The paper advocates appropriate industrial policy intervention, targeting the 'structural external imbalances' of these peripheral countries by supporting their tradable sectors.

Bianchi and Labory 2018 frames industrial policies as key instruments in managing transitional medium-term dynamics in economic systems, in particular in the context of radical structural changes involving organisational modes and markets. The paper focuses on those radical shifts stemming from restructuring of production and 
organisational processes, leading to 'industrial revolutions' between different manufacturing regimes. These transitions between manufacturing regimes have involved two main dimensions of production - i.e. volume and variety - and resulted in the movement from craft production to mass production, then from mass production to flexible production, and later from flexible production to customised mass production. Industrial revolutions, from the first to the on-going fourth one, are analysed through the lens of manufacturing regimes and with respect to specific policy areas, including competition and skills policies.

Within this overall framework, the second group of papers in this special issue investigates the micro-structural and organisational dynamics of production. They do so by engaging with three different key industrial policy issues, namely the setting-up of national system of industrial innovation (Best, 2018), the development of knowledge, skills and organisational capabilities (Khan, 2018), and impacts of corporate governance and incentive structures on investments in productive capabilities (Lazonick, 2018).

Best 2018b uses World War II as a historical laboratory to examine the origins of America's unique 'systemic capabilities' - its industrial and innovation institutions and the way in which industrial policy was used to create new industrial sectors and transform the existing ones. His papers shows how the US did not simply correct for market failure during WWII. Instead, it designed and fostered permanent organizational changes in the productive structures of the economy. This was achieved by focusing on the measurement, coordination and transformation of production and the setting up of a number of agencies and institutions providing key technology and innovation services. The paper highlights how the strategy to integrate mass production with technological innovation during WWII teaches us that we need to re-link production and innovation in today's industrial policy.

Khan 2018 focuses his attention on the organisational factors constraining productivity growth and competitiveness in entering increasingly higher-valued activities in developing countries, with a focus on the emergence of the garments industry in Bangladesh and the challenges facing its upgrading. The paper builds and expands on the classic distinction between codified knowledge and practical knowhow or skills, by focusing on the role that organisational capabilities play in extracting value from these two types of knowledge. It points out, without the capabilities to organize production competitively, how educated and skilled people cannot be employed profitably and how investments in both codified and practical knowledge can fail to achieve adequate returns. Finally, it stresses how the development of different ranges of organizational capabilities requires targeting interdependent knowledge gaps and how the policies that can fill the gaps will have to be designed in a way that is feasible in the country political economy context.

Lazonick 2018 focuses its attention on the way in which stock-based executive pay undermines investments in productive capabilities and provides empirical evidence on how this has negatively affected innovative enterprises in the US over the last three decades. Building on his theory of the innovative enterprise, Lazonick points to the critical role that senior corporate executives play in allocating corporate resources to investments and shows how these decisions are influenced by the system of executive pay. In particular, if this system incentivizes top corporate executives to make 
allocation decisions to boost the company's stock price, then they will tend to increase the company's stock price by speculation and manipulation. The paper also suggests ways to design a regulatory reform that goes beyond todays' dominant "shareholder value maximisation” paradigm.

The third group of papers expands on the meso- and micro-level production transformation analyses in the preceding part of the special issue, by focusing on the ways in which different types of financial systems and institutions, alongside the central bank and other institutions of macroeconomic management, play a role in the political economy of production transformation.

The paper by Lechevalier, Debanes and Shin, 2018 analyses the revival of industrial policies from the late 2000s in Japan and Korea and their current limitations. In doing so, the paper embraces a historical institutionalist perspective, which focuses on the evolution of the relation between financial systems and industrial policies in these two countries. This paper highlights how in both countries, in the current context of liberalized financial systems, past institutional complementarities between financial and industrial institutions developed under the so-called developmental state regime have weakened and contradictions have arisen in the implementation of industrial policy. In particular, governments have failed in subordinating finance to its ambitious industrial policy goals. However, a more granular and context -pecific comparative analysis also reveals how significant differences in the initial institutional arrangements and in the process of institutional change have resulted in greater state capabilities in Korea than in Japan.

Ferraz and Coutinho, 2018 provides a different perspective on the financial system, specifically the role that development banks can play in driving production transformation in emerging economies. The paper develops an analytical framework and an evaluation methodology to analyse different institutional forms and functions of the development banks and their policy capacities and impacts. This framework is then deployed in an in-depth insider analysis of one of the world's biggest development banks, the Brazilian Development Bank, BNDES. In particular the paper analyses the extent to which BNDES responded to investment policy directives and the consequences its finance had in the Brazilian economy between 2007 and 2015. The paper finds a number of positive impacts, especially in expanded utilities, production capacities and productive capabilities among companies in Brazil.

The paper by Nissanke 2018 explores the extent to which different types of macroeconomic frameworks are more or less conducive to structural transformation, with specific reference to the Sub-Saharan economies. Building on a critique of conventional macroeconomic policy frameworks centred on maintaining price stability, the paper points to the importance of managing a range of macroeconomic parameters in several policy domains, including fiscal, monetary and financial policies. Each of them have critical impact on a country's structural transformation. The paper advances a macroeconomic approach for the Sub-Saharan countries towards a resolution of the short-run trade-off between the macroeconomic policy objectives of stabilisation and the long-term enhancement of both aggregate demand and supply capacities. 
The last two papers point to the links between structural dynamics and political economy dynamics in industrial policy - in particular the way in which changes in political settlements can affect industrial policy outcomes (Sen and Tyce, 2018) and the way in which the political economy of industrial policy is shaped by the complex processes of the management of structural interedependencies, policy alignment, and conflict management (Andreoni and Chang, 2018).

Sen and Tyce 2018 focuses on the changes in the political settlements in Malaysia and Thailand, both of which had once been depicted as 'miracle' economies until the mid1990s, in the post-Asian financial crisis years of the late 1990s. The paper explains the prolonged growth slowdowns of these two economies since the crisis by the changes in political settlements after the crisis. The paper finds that, before the crisis, the growth strategy in these countries relied on open deals with most firms in the export-oriented manufacturing sector and closed deals with politically connected firms in the natural resource and services sectors. With the emergence of a vulnerable authoritarian political settlement in both countries after crisis, such a dualistic strategy became patronage based and led to prolonged growth slowdowns.

The paper by Andreoni and Chang, 2018 provides a novel political economy framework integrating a number of different policy domains and policy issues discussed by several papers in this special issue. Building on a long-term analytical perspective of the industrial policy debate, the paper debunks the current mainstreaming of industrial policy and provide an alternative theoretical grounding centred around three fundamental issues. First, the paper argues that industrial policy mainly deals with structural interdependencies, tensions and dualism, arising in the industrialisation process. Second it points out that countries can rely on different varieties institutions for their industrialisation and that the success of their industrialisation depends on the extent to which these institutions and policies operate in alignment. Third, the paper highlights the role of the government in conflict management, alongside its entrepreneurial function, and emphasises the importance of government organisational capabilities in performing these functions. The paper concludes by offering a tool - i.e. Policy Package Matrix - aimed at operationalising the theoretical framework and at improving the strategic coordination of packages of interactive industrial policy measures.

\section{References (to add references to contributions in the special)}

Andreoni, A. 2014. Structural Learning: Embedding Discoveries and the Dynamics of Production, Structural Change and Economic Dynamics, 29,58-74.

Andreoni, A. 2015. On Manufacturing Development under Resources Constraints, in M. Baranzini, C. Rotondi, and R. Scazzieri (eds.), Resources, Production, and Structural Dynamics, Cambridge, Cambridge University Press, pp. 407-23.

Andreoni, A. 2016. Varieties of Industrial Policy: Models, Packages and Transformation Cycles, in Noman, A. and Stiglitz, J. (eds.), Efficiency, Finance and Varieties of Industrial Policy, New York, Columbia University Press, 245305. 
Andreoni, A. 2017. Strategies for Emerging Technologies and Strategic Sectors: Evidence from OECD countries and some reflections on the Italian case, L'industria, XXVIII, 1, 3-14.

Andreoni, A. 2018. The Architecture and Dynamics of Industrial Ecosystems: Diversification and Innovative Industrial Renewal in Emilia Romagna, Cambridge Journal of Economics, , 42, 6.

Andreoni, A. and Scazzieri, R. 2014. Triggers of Change: Structural Trajectories and Production Dynamics, Cambridge Journal of Economics, 38(6), 1391-1408.

Andreoni A. and Chang H.-J. 2016. Industrial Policy and the Future of Manufacturing, Economia e Politica Industriale, 43,4,491-502.

Andreoni, A. and Chang, H.-J. 2017. Bringing Production and Employment back into Development, Cambridge Journal of Regions, Economy and Society, 10,173187.

Andreoni, A., Frattini, F. and Prodi, G. 2017. Structural Cycles and Industrial Policy Alignment: The Private-Public Nexus in the Emilian Packaging Valley, Cambridge Journal of Economics, 41,3,881-904.

Andreoni, A. and Tregenna, F. 2018. Stuck in the Middle: Premature Deindustrialisation and Industrial Policy, IDTT Working paper 11/2018, University of Johannesburg.

Andreoni, A., Chang, H-J, Konzelmann, S. and A. Shipman. 2018. The Dynamics of Economic and Industrial Renewal in Mature Economies, Cambridge Journal of Economics, 42, 6.

Andreoni and Chang, 2018 in this special issue

Berger, S. 2013. Making in America, Cambridge, MA, MIT Press.

Best, M. (2018a) How Growth Really Happens. The Making of Economic Miracles through Production, Governance, and Skills, Princeton and Oxford, Princeton University Press.

Best, 2018b in this special issue

Bianchi and Labory, 2018 in this special issue

Block, F. and Keller, M. 2011. State of Innovation. The U.S. Government's Role in Technology Development, Routledge.

Chang, H-J. 1994a. The Political Economy of Industrial Policy, Basingstoke, Macmillan.

Chang, H.J. 1994b. State, Institutions and Structural Change, Structural Change and Economic Dynamics, 5, 2, 293-313.

Chang, H-J. 2002a. Kicking Away the Ladder - Development Strategy in Historical Perspective, London, Anthem Press.

Chang, H-J. 2002b. Breaking the Mould - An Institutionalist Political Economy Alternative to the Neo-Liberal Theory of the Market and the State, Cambridge Journal of Economics, 26, 5.

Chang, H-J. 2011a. Industrial Policy: Can We Go Beyond an Unproductive Confrontation?' in J. Lin and B. Pleskovic, (eds.), Annual World Bank Conference on Development Economics 2010, Global: Lessons from East Asia and the Global Financial Crisis, Washington, DC, World Bank.

Chang, H-J. 2011b. Institutions and Economic Development: Theory, Policy, and History, Journal of Institutional Economics, 7, 4.

Chang, H-J. and Andreoni, A. 2019. 'Institutions and the Process of Industrialisation: Towards a Theory of Social Capability Development', in Nissanke, M. and J.A. 
Ocampo, eds., The Palgrave Handbook of Development Economics: Critical Reflections on Globalization and Development, Palgrave.

Ferraz and Coutinho, 2018 in this special issue

Foray, D., Mowery, D. and R. Nelson. 2012. The Need for a New Generation of

Policy Instruments to Respond to the Grand Challenges, Research Policy, 41,10,

1697-1792.

Khan, 2018 in this special issue

Landesmann, M. and Scazzieri, R. (1996a) 'The Production Process: Description and

Analysis', in M. Landesmann and R. Scazzieri (eds.), Production and Economic

Dynamics, Cambridge, Cambridge University Press, pp. 191-228.

Landesmann, M. and Scazzieri, R. (1996b) 'Forms of Production Organisation: The

Case of Manufacturing Processes', in M. Landesmann and R. Scazzieri (eds.),

Production and Economic Dynamics, Cambridge, Cambridge University Press, pp. 252-303.

Landesmann and Stollinger, 2018 in this special issue

Lazonick, 2018 in this special issue

Lechevalier, Debanes and Shin, 2018 in this special issue

Marengo, L. and Scazzieri, R. 2014. Embedding Production, Special issue, Structural

Change and Economic Dynamics, 29, 1-88.

Nissanke, 2018 in this special issue

Pasinetti, L.L. (1981) Structural Change and Economic Growth. A Theoretical Essay on the Dynamics of the Wealth of Nations, Cambridge, Cambridge University Press.

Quadrio Curzio, A. (1996) 'Production and Efficiency with Global Technologies', in M. Landesmann and R. Scazzieri (eds.), Production and Economic Dynamics, Cambridge, Cambridge University Press, pp. 105-26.

Rodrik, D. 2014. Green Industrial Policy, Oxford Review of Economic Policy, 30, 3, 469-491.

Rosenberg, N. 1982. Inside the Black Box, Cambridge, Cambridge University Press.

Scazzieri, R. (1993) A Theory of Production. Tasks, Processes, and Technical Practices, Oxford, Clarendon Press.

Scazzieri, R. (1999) 'A Theory of Resilient Flow-Fund Linkages', in K. Mayumi and J.M. Gowdy (eds.), Bioeconomics and Sustainability. Essays in Honour of Nicholas Georgescu-Roegen, Cheltenham, UK and Northampton, Massachusetts, pp. 229-256.

Scazzieri, R. 2014. A Structural Theory of Increasing Returns, Structural Change and Economic Dynamics, 29, 75-88.

Simon, H. 1991. Organisations and Markets, Journal of Economic Perspectives, 5,2, 25-44.

Sen and Tyce 2018 in this special issue

Soete, L. 2007. From Industrial to Innovation Policy, Journal of Industrial Competitiveness and Trade, 7, 273-284.

Stiglitz, J. and Lin, J.Y. . 2013. Eds., The Industrial Policy Revolution I, Basingstoke, Palgrave.

Stiglitz, J., Lin, J.Y., and Patel, E. 2013. Eds., The Industrial Policy Revolution II, Basingstoke, Palgrave.

Syrquin, M. (1988) 'Patterns of Structural Change', in H. Chenery and T.N. Srinivasan (eds.), Handbook of Development Economics, Amsterdam and New York, Elsevier, pp. 203-73. 
Zhou, Y., Lazonick, W. and Y. Sun. 2016. Eds. China as an Innovation Nation, Oxford: Oxford University Press. 